\title{
Caracterização e avaliação da atividade pozolânica das cinzas provenientes da queima de carvão mineral das termelétricas do Pecém, Ceará, Brasil
}

\author{
Characterization and evaluation of the pozzolanic \\ activity of ash from the burning of mineral coal from \\ the Pecém thermelectric plants, Ceará, Brazil
}

Miguel Adriano Gonçalves Cirino ${ }^{1}$, Antonio Eduardo Bezerra Cabral ${ }^{2}$, David Alison Araújo Silva², Kalil Nobrega Hissa Sampaio ${ }^{2}$

\footnotetext{
${ }^{1}$ Universidade Regional do Cariri - URCA, Av. Leão Sampaio, 107, Lagoa Seca, 63041-145, Juazeiro do Norte, Ceará, Brasil.

${ }^{2}$ Universidade Federal do Ceará -UFC, PEC/DEECC, Av. Mister Hull, s/n - Pici, CEP 60455-760, Fortaleza, Ceará, Brasil.

e-mail: miguel.goncalves@urca.br, eduardo.cabral@ufc.br, davidaraujoufc@gmail.com, kalilsampaio@hotmail.com
}

\section{RESUMO}

A tendência de estabilização do consumo de carvão mineral, observada até 2019, foi interrompida devido a pandemia de Sars-Cov 2 que afetou a produção energética baseada em carvão mineral, reduzindo a demanda mundial deste produto. A queima do carvão mineral para a produção energética em usinas termelétricas geram grandes quantidades de resíduos, como as cinzas leves (fly ash), proveniente de processos eletrostáticos e as cinzas de fundo (botton ash), provenientes de processos de dessulfuração do gás da chaminé (Flue Gas Desulfurization - FGD). Em muitos os resíduos são estocados em depósitos ao ar livre, tornando-se um potencial risco ao meio ambiente e aos ecossistemas circunvizinhos. Com vistas a melhorar compreensão das características destes resíduos, buscou-se caracterizar a cinza leve (CV1) e da cinza de fundo (CV2), resíduos provenientes das usinas termelétricas do Pecém I e II, localizadas no estado do Ceará/Brasil, quanto aos parâmetros químicos e físicos por meio de ensaios de composição química por FRX (Fluorescência de Raios X) e EDS (Espectroscopia de Energia Dispersiva), teor de umidade, perda ao fogo, teor de resíduos insolúveis, massa específica, finura pelo método de permeabilidade ao ar, caracterização granulométrica, avaliação microestrutura por MEV (Microscopia Eletrônica de Varredura), termogravimentria, determinação das fases mineralogia por DRX (Difração de Raios X) e avaliação da atividade pozolânica. Evidenciou-se que a CV1 apresenta características compatíveis com cinzas volantes tipo $\mathrm{C}$ e atividade pozolânica. Para a cinza CV2, observou-se que não foram atendidos aos requisitos químicos de atividade pozolânica, apresentando também altos teores de trióxido de enxofre e fases cristalinas como a Calcita, provenientes do processo de dessulfuração FGD. Em ambos os casos, as cinzas podem ser utilizadas em compostos cimentícios, desde que compatíveis com as características apresentadas, possibilitando assim a redução e acúmulo do material nas usinas, reduzindo os riscos ao meio ambiente.

Palavras-chave: Cinza leve; Cinza de fundo; Caracterização físico-química; Atividade pozolânica.

\section{ABSTRACT}

The trend towards stabilization of coal consumption, observed until 2019, was interrupted due to the SarsCov 2 pandemic that affected energy production based on mineral coal, reducing the world demand for this product. The burning of mineral coal for energy production in thermal power plants generates large amounts of waste, such as light ash (fly ash), from electrostatic processes and background ash (botton ash), from desulfurization processes of the chimney gas (Flue Gas Desulfurization - FGD). In many residues, they are 
stored in open air deposits, becoming a potential risk to the environment and the surrounding ecosystems. In order to improve understanding of the characteristics of these residues, we sought to characterize light ash (CV1) and bottom ash (CV2), residues from the Pecém I and II thermoelectric plants, located in the state of Ceará / Brazil, regarding chemical and physical parameters by means of chemical composition tests by FRX (X-Ray Fluorescence) and EDS (Dispersive Energy Spectroscopy), moisture content, loss to fire, insoluble residue content, specific mass, fineness by air permeability method, granulometric characterization, microstructure evaluation by SEM (Scanning Electron Microscopy), thermogravimentation, determination of the mineralogy phases by XRD (X-Ray Diffraction) and evaluation of pozzolanic activity. It was evidenced that $\mathrm{CV} 1$ has characteristics compatible with type $\mathrm{C}$ fly ash and pozzolanic activity. For CV2 ash, it was observed that the chemical requirements for pozzolanic activity were not met, also presenting high levels of sulfur trioxide and crystalline phases such as Calcite, from the FGD desulfurization process. In both cases, the ashes can be used in cementitious compounds, as long as they are compatible with the characteristics presented, thus enabling the reduction and accumulation of material in the plants, reducing the risks to the environment.

Keywords: Fly ash; Botton ash; Physico-chemical characterization; Pozzolanic activity.

\section{INTRODUÇÃO}

A demanda por carvão mineral apresentou uma tendência de flutuação negativa entre os anos de 2014 a 2019, relacionada com o aumento do uso de fontes renováveis de energia e ocorrências circunstanciais em algumas regiões do mundo, sendo provável que seja uma tendência seja duradoura. Com tudo, para a projeção dos próximos cinco ano, é que a capacidade de geração e produção de energia e a demanda por carvão devam se manter em patamares estáveis, dependendo do consumo de energia elétrica e das políticas climáticas, do preço do gás natural e da procura pelo carvão mineral em países do sudeste asiático e Rússia [1].

No entanto, com os bloqueios implementados em resposta ao surto de Sars-Cov 2 (Covid-19) reduziram drasticamente o uso de eletricidade e a produção industrial na maioria dos países, reduzindo o consumo global de carvão, a partir do primeiro semestre de 2020. Porém, devido aos custos relacionados à estocagem do montante de resíduos gerados em usinas termétricas, alinhado às necessidades do uso de fontes de energia à base de carvão mineral, implicam-se na necessidade dar um destino adequando aos resíduos proveniente de sua queima [2].

Segundo dados da ANEEL [3], quanto a produção de energia à base de carvão mineral, verifica-se que o setor energético brasileiro possui $164.747 .269 \mathrm{~kW}$ de potência instalada proveniente das Usinas Elétricas (UE), contando com 14 unidades de Usinas Termelétricas (UTE) que utilizam o carvão mineral como principal fonte energética, com capacidade de produção de 3.323.740 KW. Encontra-se no Pecém/CE as UTEs das empresas EDP Brasil e ENEVA, Pecém I e Pecém II, com potência de 1085 MW, que utilizam o carvão mineral proveniente do Nordeste da Colômbia, o que representa cerca de $32 \%$ da potência total de UTE no Brasil, sendo a maior em termo de potência [4].

O carvão mineral é definido como sendo uma rocha sedimentar composta por constituintes orgânicos (em menores frações) e inorgânicos, sendo caracterizado como uma mistura heterogênea complexa de fases sólidas, líquidas e gasosas [5,6]. No processo de queima do carvão mineral, em usinas termelétricas, para a produção de energia elétrica, são gerados subprodutos residuais como as escórias de caldeiras, monóxido e dióxido de carbono, e aumento da concentração de óxidos sulfurosos $\left(\mathrm{SO}_{\mathrm{X}}\right)$, que tem impacto negativo sobre o meio ambiente e saúde humana [7,8] compostos orgânicos voláteis, cinzas de cinzas de combustão do carvão mineral (CCCM) como as cinzas de dessulfuração dos gases de combustão (FGD), e em maiores proporções, as cinzas leves (fly ash) e as cinzas de fundo (botton ash) [9], as quais são detalhadas conforme [10]:

a) Escórias de caldeira (boiler slag) - são produzidas durante a combustão de carvão granulado em grelhas móveis, sendo geralmente retiradas pelo fundo da fornalha, após serem resfriadas com água. Apresentam granulometria grosseira e blocos sintetizados, contendo teores significativos de carbono (5\% a $20 \%$ ) e/ou material orgânico. b) Cinzas de fundo (botton ash) - são cinzas de granulometria média (maiores que 150 $\mu \mathrm{m})$, que caem para o fundo das fornalhas de queima de carvão pulverizado ou de leito fluidizado, podendo ser retiradas secas ou através de um fluxo de água. c) Cinzas volantes (fly ash) - são cinzas leves constituídas de partículas muito finas $(100 \%$ menor que $150 \mu \mathrm{m})$, encontradas no fluxo do gás da chaminé, podendo ser coletado nos precipitadores eletrostáticos, em filtros mecânicos ou liberadas para a atmosfera. d) Cinza de dessulfuração do gás da chaminé (flue gas desulfurization - FGD) - São obtidas devido a passagem dos gases da combustão do carvão mineral por um meio aquoso alcalino, resultando em combinação de cinza volante, sais de $\mathrm{Ca}-\mathrm{S}$ (sulfito e/ou sulfato de cálcio) e carbonato de cálcio $\left(\mathrm{CaCO}_{3}\right)$, originado um resíduo com elevado teor de Trióxido de enxofre $\left(\mathrm{SO}_{3}\right)[11,12]$. 
As cinzas de carvão mineral, diferenciam-se quanto a morfologia, a fração granulométrica, a densidade, a composição química, o teor de umidade, as características mineralógicas e dos resíduos inorgânicos presentes no material [13]. Fatores estes dependentes da composição do carvão mineral e da eficiência dos equipamentos utilizados no processo [9]. Estes resíduos são definidos como materiais silicoaluminosos que reagem como hidróxido de cálcio, formando o silicato de cálcio hidratado em matrizes cimentícias e apresentam forma predominantemente esféricas e diferenciam-se quanto ao tipo e quantidade de microesferas finas, com morfologia predominante vítrea. [14, 15].

Quanto à composição química, ambas as cinzas apresentam composições similares aos materiais cerâmicos, compostas por fases baseadas em óxidos de silício, alumínio, ferro e cálcio, totalizando cerca de noventa por cento do material, e a composição restante apresenta proporções de óxidos de magnésio, sódio, potássio, titânio, enxofre e resíduos não voláteis [16] As cinzas leves correspondem a cerca de oitenta por cento do total de resíduos gerados na queima do carvão mineral [17].

As cinzas de fundo apresentam aparência de grãos semifundidos que se depositam no fundo das caldeiras e, são transportadas por arrasto hidráulico e depois são depositadas em pátios de armazenamento. Quimicamente apresentam altos teores de óxidos de ferro e carbono e menores teores de óxidos de alumínio, quando compradas com as cinzas leves [18].

Quanto à produção de cinzas no Brasil, os estados do Rio Grande do Sul, Maranhão e Ceará são os maiores produtores de cinzas da queima de carvão mineral, com produção anual de 2,66 milhões de toneladas/ano de cinza volante e 396.210 toneladas/ano de cinza obtidas por processo FGD (dados referentes ao ano base de 2016). O estado do Rio Grande do Sul apresentou 2,1 milhões de toneladas/ano de cinza volante, com uma perspectiva de aumento para 5,9 milhões de toneladas/ano de cinza volante e 267.000 toneladas/ano de cinza de FGD e o estado do Maranhão (MA) tem-se uma geração de 83.950 toneladas/ano de cinza volante e 52.560 toneladas/ano de cinza de FGD [19]. As cinzas geradas na UTE do Pecém, em regime de operação plena, somavam em 2016, cerca de 69.350 toneladas de cinza de fundo por ano, 328.500 toneladas/ano de cinzas volantes e 76.650 toneladas/ano de cinza FGD [20].

Muitas pesquisas problematizam a utilização do carvão mineral como fonte de energia, por ser uma das principais fontes de emissão de gases causadores do aquecimento [21]. Fato relacionado também à geração de grande volume de resíduos potencialmente danosos ao meio ambiente que podem lixiviar compostos potencialmente de corpos aquáticos, solos e águas subterrâneas, afetando a biodiversidade dos ecossistemas do entorno dos pátios de deposição [22]. No entanto, a utilização das cinzas de carvão mineral ainda é pouco expressiva no mundo, onde cerca de trinta por cento das cinzas são reaproveitados, como exemplo, na fabricação de cimentos [23].

Para minimizar os impactos, observa-se na literatura a possibilidade de utilização dos resíduos oriundos da queima do carvão mineral como carga ou adições no processo de fabricação de cimentos, composição de vidros e cerâmicas, produção de geopolímeros, zeólitas, produção de argamassas, concretos, estabilizadores de camadas de estradas e melhorador de adesividade em misturas asfálticas [24- 29]. Destacando-se também, potenciais aplicações na área ambiental como extração de metais como alumínio, ferro, cromo, cádmio e mercúrio [30, 31].

Neste contexto, devido ao grande volume de cinzas da combustão de carvão mineral produzidos na unidades Termelétricas do Pecém/CE, surgiu a necessidade de caracterizar os resíduos, que servirão de base para soluções sustentáveis e econômicas locais, como a utilização das cinzas em pastas de cimentos Portland, argamassas e concretos em outras pesquisas. Proporcionando assim, base para soluções práticas que busquem a redução do montante estocado nos pátios, além de contribuir com informações importantes que ampliam as possibilidades de aplicações ou comparações entre resíduos.

Para tal, o objetivo deste artigo é o de caracterizar as cinzas da combustão de carvão mineral da termelétrica do Pecém/CE, quanto às propriedades físicas, químicas, mineralógicas, térmica, granulométricas dos resíduos e avaliação da atividade pozolânica.

\section{MATERIAIS E MÉTODOS}

Foram caracterizadas as cinzas da combustão de carvão mineral (CCCM) leves, denominada CV1 e, a cinza de fundo CV2, ambas provenientes provenientes das Usinas Termelétricas Energia Pecém, localizada no município de São Gonçalo do Amarante, Ceará, Brasil. Para a avaliação da atividade pozolânica, utilizou-se o Cimento Portland, o hidróxido de cálcio e a água da rede de abastecimento público, conforme indicado pela ABNT NBR 5751:2015 [32] e ABNT NBR 5752:2014 [33]. 


\subsection{Primeira etapa metodológica}

As cinzas foram coletadas manualmente e, de maneira aleatória, sob orientação dos responsáveis técnicos, nos pátios de deposição de resíduos da UTE Pecém. Após a coleta, o material foi acondicionado em sacos plásticos e levado para armazenagem em depósitos, protegidos de intemperes, nas dependências da Universidade Federal do Ceará (UFC), Fortaleza, Brasil.

As amostras foram separadas, homogeneizadas e pesadas, onde utilizou-se balança de digital de precisão Tecnal Mark modelo 3100 com resolução de 0,01g. Nesta etapa também foi realizada a preparação das amostras para a caracterização, conforme orientação indicada nas normas técnicas referentes a cada ensaio.

\subsection{Segunda etapa metodológica}

A etapa de caracterização das CCCM corresponde aos ensaios de caracterização química, de propriedades físicas, conforme apresentada na Tabela 1. Avaliou-se também a análise térmica, morfológica e mineralógica das cinzas.

Tabela 1: Ensaios de caracterização química e de propriedades físicas das CCCM.

\begin{tabular}{l|l}
\hline ENSAIO & NORMA TÉCNICA \\
\hline Fluorescência de Raios-X - FRX & ABNT NBR 14656:2016 [34] \\
\hline Teor de Umidade & ABNT NBR NM 24:2003 [35] \\
\hline Teor de óxidos de cal livre & ABNT NBR 7227:2012 [36] \\
\hline Teor de resíduos insolúveis & ABNT NBR NM 15:2012 [37] \\
\hline Perda ao fogo & ABNT NBR NM 18:2012 [38] \\
\hline Massa específica & ABNT NBR NM 23:2001 [39] \\
\hline Finura pelo método de permeabilidade ao ar & ABNT NBR 16372: 2015 [40] \\
\hline
\end{tabular}

a) Composição química (FRX): Determinou-se os principais óxidos presentes nas amostras, realizado por análise de FRX. Para a realização do ensaio, utilizou-se o equipamento ZSXMini II - Rigaku para quantificação de elementos do Flúor ao Urânio, pertencente ao Departamento de Física da UFC. A preparação e a realização do ensaio seguiu a determinação prescrita na ABNT NBR 14656:2016 [34], onde foram feitas pastilhas prensadas com diâmetro de $3 \mathrm{~cm}$, com massa aproximada de 1 grama para cada amostra das cinzas leve e de fundo.

b) Teor de umidade e Cal livre: A cal livre é decorrente de uma combinação não completa do óxido de cálcio ou não dissolvida residual (em resíduos como as cinzas da combustão de carvão mineral) ou da dissociação do silicato tricálcico em matrizes cimentícias [41]. O teor de umidade expressa a quantidade de água presente na amostra, sendo um importante parâmetro para aplicação em compostos cimentícios. Ambos os ensaios foram realizados nos laboratórios de análises de cimentos pertencentes a uma indústria cimenteira. A preparação das amostras e realização dos ensaios seguiram as recomendações das Normas ABNT NBR NM 24:2003 [35] e ABNT NBR 7227:2012 [36].

c) Massa Específica: A massa específica foi determinada seguindo os procedimentos referidos na ABNT NBR NM 23:2001[21], realizada no laboratório de Materiais e Construção Civil da UFC.

d) Determinação do teor de resíduos insolúveis: Correspondem ao percentual do material não solúvel e não cimentante, oriundos do processo de calcinação e, quando utilizado em materiais cimentícios, não faz parte das reações de hidratação [42]. A análise química para a determinação de resíduo insolúvel, seguiu as recomendações prescritas na ANBT NBR NM 15:2012 [22], sendo uma norma relacionada aos cimentos Portland, adaptada para a avaliação das cinzas de carvão mineral.

e) Perda ao fogo: A perda ao fogo indica a massa residual de carbono nas cinzas e substâncias inertes, importante parâmetro para se determinar a qualidade da cinza, quanto à eficiência da queima do carvão [43]. O ensaio seguiu as recomendações prescritas pela ABNT NBR NM 15:2012 [38]. O ensaio foi realizado nos laboratórios de análises de cimentos pertencentes à uma indústria cimenteira.

f) Determinação da fração granulométrica (Finura pelo método de Blaine e granulometria à laser): $\mathrm{O}$ ensaio busca avaliar a superfície específica do material e a uniformidade das partículas no processo de moagem ou produção do material, podendo ser relacionado à distribuição granulométrica, forma e finura dos grãos, relaciona-se com a reatividade e interação entre partículas do material [44]. Para a determinação da distribui- 
ção granulométrica das CCCM, utilizou-se o Granulômetro à laser CILAS 920L da Universidade Federal do Rio Grande do Norte (UFRN).

g) Caracterização morfológica (MEV e EDS): Utilizou-se o microscópio eletrônico de varredura da marca HITACHI TM 3000 com periférico acoplado tipo EDS SWIFT ED 3000, do Departamento de Geologia da UFC. Ao se realizar no MEV, optou-se pela realização da análise de EDS (Energy Dispersive Detector $X$-Ray), que busca avaliar a composição química da amostra avaliada.

h) Análise térmica (TG e TGA): Foi utilizado o equipamento ao pertencente ao Laboratórios de Cimentos - LABCIM/UFRN. As amostras foram pesadas com massa entre $10 \mathrm{mg}$ a $15 \mathrm{mg}$, e inseridas em um cadinho de alumina e ensaiadas no equipamento da marca Shimadzu DTG-60, com razão de aquecimento de $10^{\circ} \mathrm{C} / \mathrm{min}$, com atmosfera de Nitrogênio, vazão de $100 \mathrm{ml} / \mathrm{min}$ e variação de temperatura entre a ambiente (temperatura de aproximadamente $22^{\circ} \mathrm{C}$ ) até a temperatura máxima de $900^{\circ} \mathrm{C}$ e, para obter as curvas referentes às análises térmicas, utilizou-se o aplicativo TA universal analysis [45].

i) Análise mineralógica (DRX): Para a identificação das fases policristalinas presentes nas amostras, utilizou-se o Difratômetro de raios-X Shimadzu - modelo 7000, com tudo de raio-X de 60W e 100-240 V 50/60 $\mathrm{Hz}$, com varredura entre $5^{\circ}$ a $80^{\circ}$ (em 2 Ө), tamanho de passe de $0,02^{\circ}$ pertencente ao LABCIM/UFRN.

\subsection{Terceira etapa metodológica}

$\mathrm{Na}$ terceira etapa do estudo foi realizada a avaliação da atividade pozolânica das cinzas. A atividade pozolânica foi avaliada conforme procedimentos de preparação e execução de acordo com as normas ABNT NBR NBR 5751:2015 [32], para a avaliação da atividade e pozolânica para materiais pozolânicos quanto à determinação do índice de desempenho com cimento Portland aos vinte e oito dias e ABNT NBR 5752:2014 [33], para a atividade pozolânica com cal aos sete dias. Por fim, as cinzas foram classificação segundo a ABNT NBR 12653:2014 [46]. Estes resultados serviram de embasamento em pesquisas com utilização das cinzas em componentes cimentícios como pastas de cimento, argamassas e concreto.

\section{RESULTADOS E DISCUSSÃO}

\subsection{Caracterização química das cinzas da combustão de carvão mineral}

A Tabela 1 apresenta os resultados das análises químicas por Fluorescência de Raios-X, quanto aos percentuais dos principais óxidos e perda ao fogo (PF) para as amostras das cinzas CV1 e CV2. Os valores apresentados na Tabela 2 podem ser comparados com os resultados obtidos por alguns pesquisadores e referências normativas para classificação das cinzas, conforme Tabela 3.

Tabela 2: Composição química das cinzas da combustão de carvão mineral.

\begin{tabular}{|c|c|c|c|c|c|c|c|c|c|c|c|}
\hline CINZAS & $\begin{array}{c}\mathrm{SiO}_{2} \\
(\%)\end{array}$ & $\begin{array}{c}\mathrm{Al}_{2} \mathbf{O}_{3} \\
(\%)\end{array}$ & $\begin{array}{c}\mathrm{Fe}_{2} \mathrm{O}_{3} \\
(\%)\end{array}$ & $\begin{array}{c}\mathrm{CaO} \\
(\%)\end{array}$ & $\begin{array}{c}\mathrm{CaO} \\
\text { livre }(\%)\end{array}$ & $\begin{array}{l}\mathrm{SO}_{3} \\
(\%)\end{array}$ & $\begin{array}{c}\mathrm{Na}_{2} \\
\mathbf{O} \\
(\%)\end{array}$ & $\begin{array}{l}\mathbf{K}_{2} \mathbf{O} \\
(\%)\end{array}$ & $\begin{array}{l}\mathrm{TiO}_{2} \\
(\%)\end{array}$ & $\begin{array}{c}\text { Outros } \\
\text { oxidos (\%) }\end{array}$ & $\begin{array}{l}\text { PF } \\
(\%)\end{array}$ \\
\hline CV1 & 50,33 & 18,62 & 14,96 & 6,76 & 0,10 & 1,64 & 1,37 & 2,27 & 1,40 & 1,40 & 1,83 \\
\hline CV2 & 29,97 & 10,96 & 11,05 & 31,06 & 4,04 & 10,77 & 0,75 & 1,32 & 1,10 & 2,02 & 6,57 \\
\hline
\end{tabular}

Tabela 3: Características físicas das cinzas volantes, utilizadas por diversos autores.

\begin{tabular}{c|c|c|c|c|c}
\hline PROPRIEDADES & $\begin{array}{c}\mathbf{S i O}_{2}+\mathbf{A l}_{\mathbf{2}} \mathbf{O}_{3}+\mathbf{F e}_{2} \mathbf{O}_{3} \\
(\%)\end{array}$ & $\begin{array}{c}\mathbf{S O}_{3} \\
(\%)\end{array}$ & $\begin{array}{c}\text { ÁLCALIS DISPONÍ- } \\
\text { VEIS }(\%)\end{array}$ & $\begin{array}{c}\text { CaO } \\
(\%)\end{array}$ & $\begin{array}{c}\text { PERDA AO } \\
\text { FOGO }(\%)\end{array}$ \\
\hline Bentz et al.(2015) [47] & 92,70 & 0,02 & 1,78 & 0,70 & 0,80 \\
\hline Bui et al.(2015) [48] & 90,67 & 0,36 & 1,20 & 1,26 & 2,80 \\
\hline Hoppe Filho (2008) [49] & 91,40 & 0,30 & 1,63 & 3,99 & 2,02 \\
\hline Kabay et al.(2015) [50] & 88,11 & 0,95 & - & 1,90 & 1,69 \\
\hline Mejía et al. (2015) [51] & 79,70 & 0,60 & 2,20 & 0,80 & 14,80 \\
\hline Shaikh e Supit (2015) [52] & 91,20 & 0,21 & 0,99 & 1,61 & 0,50 \\
\hline ASTM C 618-F (2019) [53] & $\geq 50$ & $\leq 5$ & - & - & $\leq 6$ \\
\hline ASTM C 618 - C (2019) [53] & $\geq 70$ & $\leq 5$ & - & - & $\leq 6$ \\
\hline ABNT NBR 12653:2014 [46] & $\geq 70$ & $\leq 5$ & $\leq 1,5$ & - & $\leq 10$ \\
\hline
\end{tabular}


De acordo com a Tabela 2, os teores de óxido de sílicio $\left(\mathrm{SiO}_{2}\right)$, óxido de ferro $\left(\mathrm{Fe}_{2} \mathrm{O}_{3}\right)$ e óxido de alumínio $\left(\mathrm{Al}_{2} \mathrm{O}_{3}\right)$, para a cinza $\mathrm{CV} 1$, são superior aos valores observados para a cinza CV2. Quando comparados os valores para os parâmetros apresentados na Tabela 3 , com os dados da Tabela 2 , observa-se que ambas as cinzas apresentam valores divergentes dos resultados encontrados pelos pesquisadores, com destaque para $\mathrm{o}$ trióxido de enxofre $\left(\mathrm{SO}_{3}\right)$ e para os óxidos $\mathrm{SiO}_{2}, \mathrm{Al}_{2} \mathrm{O}_{3}$ e $\mathrm{Fe}_{2} \mathrm{O}_{3}$.

Para a cinza CV2, destacam-se os percentuais de óxido de cálcio $(\mathrm{CaO})$ e trióxido de enxofre $(10,77 \%)$, valor superior em quatro vezes ao observado para a CV1. Estes valores são compatíveis com o processo de dessulfuração de gases de chaminé (FGD), relacionada ao processo tecnológico utilizado na UTE Pecém, que utiliza a lavagem com cal, para reduzir a concentração de compostos à base de enxofre [29]. Ainda, de acordo com a Tabela 2, a cinza CV2, apresenta teor de óxido de cálcio $\mathrm{CaO}(31,06 \%)$, valor este superior da ordem de quatro vezes o observado para a cinza CV1.

Segundo as Normas técnicas ASTM C 618:2019 [53] e ABNT NBR 12653:2014 [46], indicam-se os parâmetros de somatório dos teores dos óxidos de ferro, de alumínio e silício $\left(\mathrm{SiO}_{2}+\mathrm{Al}_{2} \mathrm{O}_{3}+\mathrm{Fe}_{2} \mathrm{O}_{3}\right)$, o teor de trióxido de enxofre $\left(\mathrm{SO}_{3}\right)$, o teor de álcalis disponíveis na base de $\left(\mathrm{Na}_{2} \mathrm{O}\right)$ e a perda ao fogo como valores para a classificação das cinzas. Assim, A cinza CV1, apresenta compatibilidade para os parâmetros indicados nas normas, conforme Tabela 3, destacando-se o percentual da somas dos óxidos de ferro, alumínio e silício com $83,91 \%$, superior ao mínimo normativo de $70 \%$, o teor de álcalis disponíveis na base de $\mathrm{Na} 2 \mathrm{O}$ com valor inferior $1,5 \%$ e a perda ao fogo com $1,83 \%$, inferior a $6 \%$. Estes resultados indicam que a cinza CV1 pode ser classificada como Cinza Volante tipo C.

Quanto a cinza CV2, não são atendidos os parâmetros de soma dos óxidos de ferro, alumínio e silício $\left(\mathrm{SiO}_{2}+\mathrm{Al}_{2} \mathrm{O}_{3}+\mathrm{Fe}_{2} \mathrm{O}_{3}\right)$, perda ao fogo e teor de trióxido de enxofre $\left(\mathrm{SO}_{3}\right)$. Para a soma dos óxidos, o valor apresentado para a cinza CV2 foi de 51,98\%, valor inferior aos indicados nas normas de $70 \%$ para a classificação como cinza tipo C. Para a perda ao fogo, a cinza CV2 apresentou 6,57\%, superior aos $6 \%$ indicados como valores máximos, conforme Tabela 2. É importante destacar o alto teor de trióxido de enxofre (10,77\%), para a cinza CV2, valor superior ao mínimo de 5\%, apontado pelas normas ASTM C 618:2019 [53] e ABNT NBR 12653: 2014 [46], como compatíveis com cinzas volantes. Sendo assim, a CV2 não classifica-se como cinza do tipo volante $\mathrm{C}$ ou $\mathrm{F}$.

As cinzas lignitas e sub-betuminosas apresentam altas concentrações de óxidos de cálcio e magnésio e baixas concentrações de óxido de sílica e ferro, bem como menor teor de carbono, se comparado com as cinzas betuminosas. Por fim, Ahmaruzzaman (2009) [54] afirma que existem poucas cinzas provenientes de carvão antracito e, por isso, não há grandes quantidades de informações para a determinar a composição químicas das cinzas oriundas desse carvão.

Ahmaruzzaman (2009) [54] tece alguns comentários sobre as características químicas das cinzas de acordo com a norma americana ASTM C 618:2019 [53], onde as cinzas provenientes do carvão subbetuminoso ou carvão lignito se enquadram como cinza tipo $\mathrm{C}$, apresentando propriedades cimentícias e pozolânicas. Por outro lado, cinzas provenientes de carvão betuminoso ou antracito se enquadram como cinza tipo F. No que tange as reações pozolânicas das cinzas, para que a mesma ocorra, é necessário que a sílica e os aluminatos reativos estejam solubilizadas. Como também a atividade pozolânica requer a presença de hidróxido de cálcio, álcalis do cimento e $\mathrm{pH}$ elevado para solubilização da fase vítrea da pozolana, resultando na formação de hidratos com maior ganho de resistência [55]. Assim, a cinza CV2 apresenta característica de cinza lignita, uma vez que apresenta elevado teor de $\mathrm{CaO}$ e a CV1 apresenta característica de cinza betuminosas [54].

\subsection{Caracterização física e granulométrica das cinzas da combustão de carvão mineral}

Os resultados para a análises de teor umidade, teor de resíduos insolúveis, finura pelo método de permeabilidade ao ar (Método Blaine) e massa especifica são apresentados na Tabela 4.

Tabela 4: Caracterização química e física das cinzas da combustão de carvão mineral.

\begin{tabular}{|c|c|c|c|c|}
\hline CINZA & $\begin{array}{c}\text { TEOR DE } \\
\text { UMIDADE (\%) }\end{array}$ & $\begin{array}{c}\text { RESÍDUOS } \\
\text { INSOLÚVEIS (\%) }\end{array}$ & $\begin{array}{l}\text { FINURA } \\
\left(\mathrm{cm}^{3} / \mathrm{g}\right)\end{array}$ & $\begin{array}{l}\text { MASSA ESPECÍFICA } \\
\left(\mathrm{g} / \mathrm{cm}^{3}\right)\end{array}$ \\
\hline CV1 & 0,35 & 88,72 & 8220 & 2,33 \\
\hline CV2 & 0,88 & 57,90 & 3760 & 2,36 \\
\hline $\begin{array}{c}\text { ABNT NBR } \\
\text { 12653:2014 [46] }\end{array}$ & $\leq 3$ & - & - & - \\
\hline
\end{tabular}


Conforme dados da Tabela 4, ambas as cinzas apresentam baixo teor de umidade, inferior ao indicado pela norma ABNT NBR 12653:2014 [46] de 3\%, para classificação como cinza volante. A cinza CV1 apresentou percentual de resíduos insolúveis 34,75\% superior ao observado para a cinza CV2 e, a massa específica da cinza CV2 é superior a observada para a cinza CV1 em 1,27\%. As massas específicas das cinzas CV1 e CV2 são inferiores ás massas específicas de cinzas volantes obtidas nas pesquisas de Bentz et al.(2015) [47]

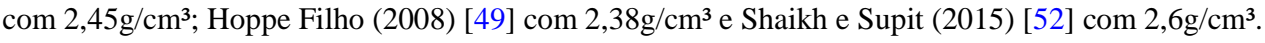

A cinza CV1 apresentou finura Blaine de $8220 \mathrm{~cm}^{3} / \mathrm{g}$ superior ao dobro da finura da cinza CV2 $\left(3760 \mathrm{~cm}^{3} / \mathrm{g}\right)$, indicando maior uma maior área superficial, para a cinza CV1, com tendência de maior demanda de consumo de água ou aditivos químicos, para manter a trabalhabilidade e propriedades reológicas, quando utilizadas em materiais cimentícios [56]. Vale ressaltar que as propriedades no estado fresco e endurecido de compostos cimentícios também são afetados pela distribuição granulométricas das cinzas e pela massa específica das cinzas $[57,58]$. Os resultados apresentados na Tabela 4 , reforçam que a cinza CV1 possui características físicas compatíveis com materiais pozolânicos.

Na Figura 1, observam-se os histogramas de distribuição granulométrica das cinzas de carvão mineral CV1 e CV2.

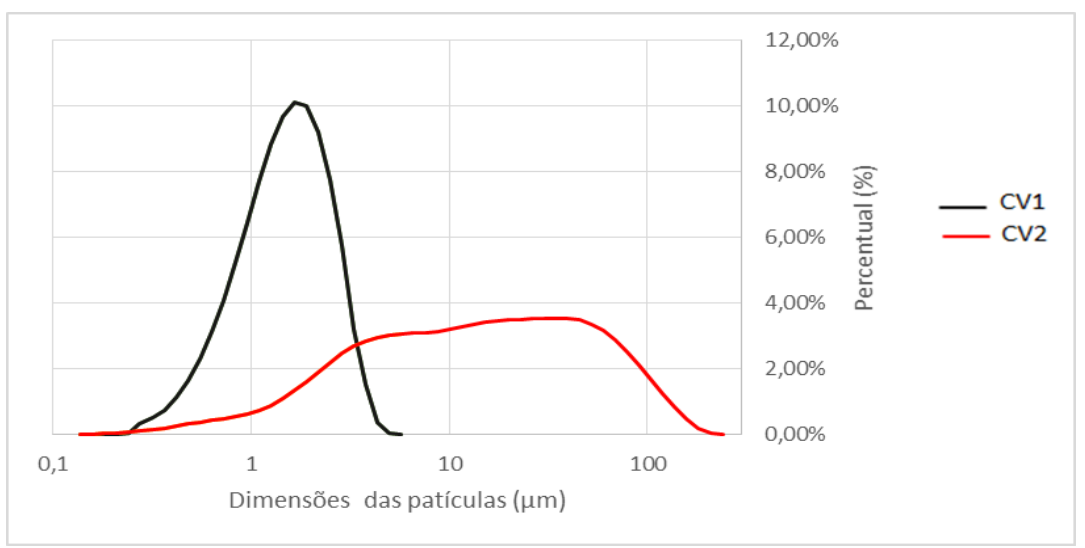

Figura 1: Distribuição granulométrica das cinzas de carvão mineral.

De acordo com as informações apresentadas na Figura 1, a distribuição granulométrica da cinza CV1 situa-se entre $0,2 \mu \mathrm{m}$ a $5,0 \mu \mathrm{m}$ e a cinza CV2 entre $0,15 \mu \mathrm{m}$ a $200 \mu \mathrm{m}$. Assim, a cinza CV2 apresenta uma distribuição média da ordem de 9,016 vezes superior ao observado para a cinza CV1, resultado que pode ser relacionado com uma superfície específica, conforme observada para finura pelo método de Blaine $\left(3760 \mathrm{~g} / \mathrm{cm}^{3}\right)$ e, consequentemente, indicando uma maior reatividade da cinza CV1 do que a cinza CV2, quanto utilizadas em compostos cimentícios, em função da maior área superficial $[59,60]$.

Quanto a frequência da distribuição granulométrica, a cinza CV2 apresenta maior amplitude na distribuição de grãos, situação oposta à observada com a cinza CV1, que possui maior concentração de partículas para os menores de diâmetro dos grãos, resultando em uma distribuição das partículas menos uniforme.

A partir das curvas das granulometrias das cinzas de carvão mineral, pode-se determinar os parâmetros granulométricos D10 (diâmetros das partículas situados no percentual igual ou inferior a 10\% da amostra), D90 (diâmetros das partículas situados no percentual igual ou inferior a 90\% da amostra), D50 (diâmetro médio das partículas) e Dmax (corresponde ao maior diâmetro dos grãos apresentado na amostra), estes parâmetros são apresentados na Tabela 5 .

Tabela 5: Diâmetros máximos dos grãos das cinzas da combustão de carvão mineral.

\begin{tabular}{c|c|c|c|c}
\hline CINZAS & D10 $(\boldsymbol{\mu m})$ & D50 $(\boldsymbol{\mu m})$ & D90 $(\boldsymbol{\mu m})$ & Dmax $(\boldsymbol{\mu m})$ \\
\hline CV1 & 0,63 & 1,44 & 2,52 & 5,012 \\
\hline CV2 & 1,91 & 13,19 & 69,00 & 209,00 \\
\hline
\end{tabular}

De acordo com os dados apresentados na Tabela 5, a cinza CV1 apresenta diâmetro máximo das partículas de 5,012 $\mu \mathrm{m}$ e D50 de 1,44 $\mu \mathrm{m}$, valores estes dentro dos limites estabelecidos pela ABNT NBR 12653:2014 [46] para classificação como cinzas volantes [15]. 
Para o parâmetro D90, a cinza CV1 apresenta grãos com diâmetros inferiores a $10 \mu \mathrm{m}$, valor compatível com a definição de materiais pozolânicos e de cinzas volantes (granulometria entre $0,5 \mu \mathrm{m}$ e $100 \mu \mathrm{m}$ ), conforme requisitos de classificação sugeridos pela norma EM 450: 2012 [61] e a norma ASTM C618:2012 [53], as quais estabelecem o percentual de $40 \%$ do material retido na peneira de 325 Tyler $(44 \mu \mathrm{m}$ de abertura de malha). Tais resultados corroboram com os dados apresentados quanto à composição química e características físicas compatíveis com cinzas volantes tipo C (para a cinza CV1). Vale destacar também que a cinza CV1 apresenta distribuição granulométrica entre $7,5 \mu \mathrm{m}$ a $150 \mu \mathrm{m}$, a qual é apontada como ideal para a obtenção de melhor desempenho como material pozolânico [62].

No que se refere a cinza CV2, indicam que o parâmetro de diâmetro médio das partículas são compatíveis com cinzas volantes $(13,19 \mu \mathrm{m})$ com inferiores ao diâmetro médio de cinzas volantes, apresentados por com valores inferiores aos observados por Bentz et al.(2015) [47] com 18,4 $\mu \mathrm{m}$; Hoppe Filho (2008) [49] com

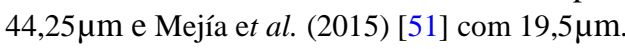

\subsection{Análise microestrutural das cinzas de combustão de carvão mineral}

Complementarmente aos resultados de caracterização granulométrica, a Figura 2 a e b, apresentam as micrografias das cinzas CV1 e CV2, realizadas por MEV.

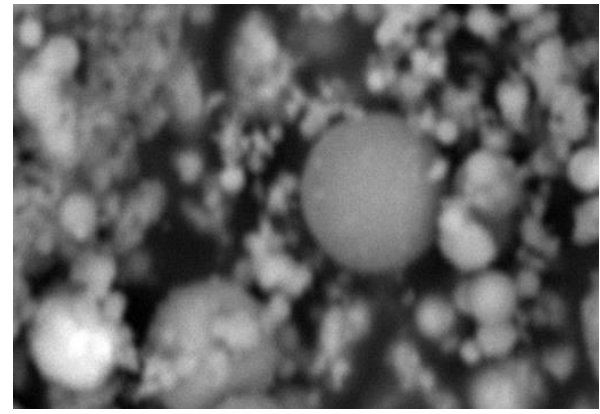

(a) CV1 - 2000X

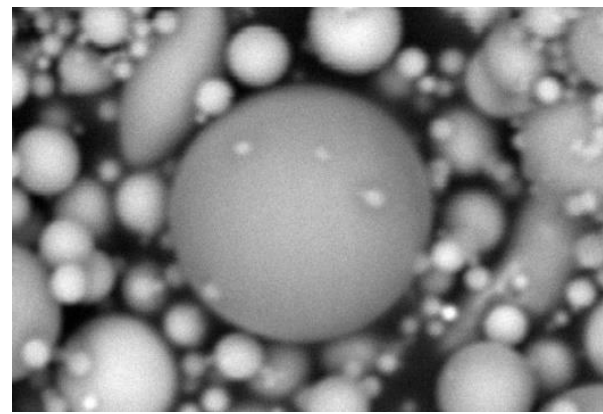

(b) CV2 - 2000X

Figura 2: Microscopia eletrônica das cinzas (a) CV1 e (b) CV2 (aumento de 2000 vezes).

Conforme Figura 2, ambas as cinzas de carvão mineral apresentam formas esféricas e superfícies lisas, diferindo-se quanto ao tamanhos médio das partículas esféricas [63]. Os maiores diâmetros foram observados para cinza CV2 e, assim, os resultados são compatíveis com a caracterização granulométrica e finura do resíduo [15]. A morfologia esférica das cinzas podem indicar uma tendências de deslizamento dos grãos, o que pode aumentar a trabalhabilidade e a fluidez de compostos cimentícios, em função do teor de substituição ou adição das cinzas nestes compostos [63-65]. Além do formato das partículas, foi realizada a análise por energia dispersiva- EDS, o qual indica os elementos químicos que estão presentes nas amostras. Os resultados para o ensaio de EDS é apresentado na Figura 3.

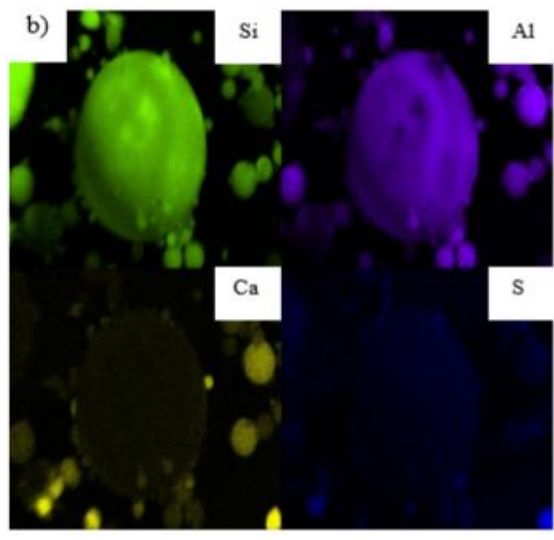

(a) EDS CV1

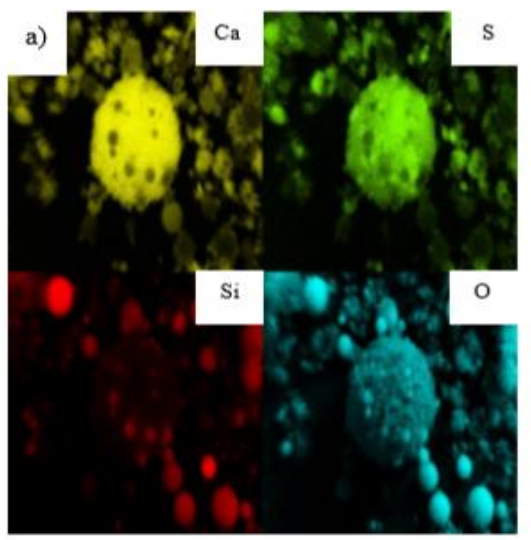

(b) EDS CV2
Onde:

$\mathrm{Si}=$ Silica

$\mathrm{Al}=$ Aluminio

$\mathrm{S}=$ Enxofre

$\mathrm{Ca}=$ Cálcio

$\mathrm{O}=$ oxigênio

Figura 3: EDS das cinzas de carvão mineral (a) CV1 e (b) CV2 
Relacionando-se os dados referentes a caracterização química e a análise por EDS, apresentado na Figura 3, observa-se a presença de silício, alumínio e cálcio, para ambas as cinzas e destaque para a presença de enxofre na cinza CV2.

\subsection{Análise térmicas das cinzas de carvão mineral}

As análises térmicas, por meio da Termogravimetria - TG, têm o objetivo de analisar a eficiência da queima do carvão mineral, por meio da determinação da massa residual de carbono [49]. Nas Figuras 4 e 5, apresentam-se as curvas termogravimétricas para as cinzas da combustão de carvão mineral CV1 e CV2.

A cinza CV1 apresenta baixa perda de massa (1,86\%), ocorrendo em três etapas, conforme apresentada na Figura 4.

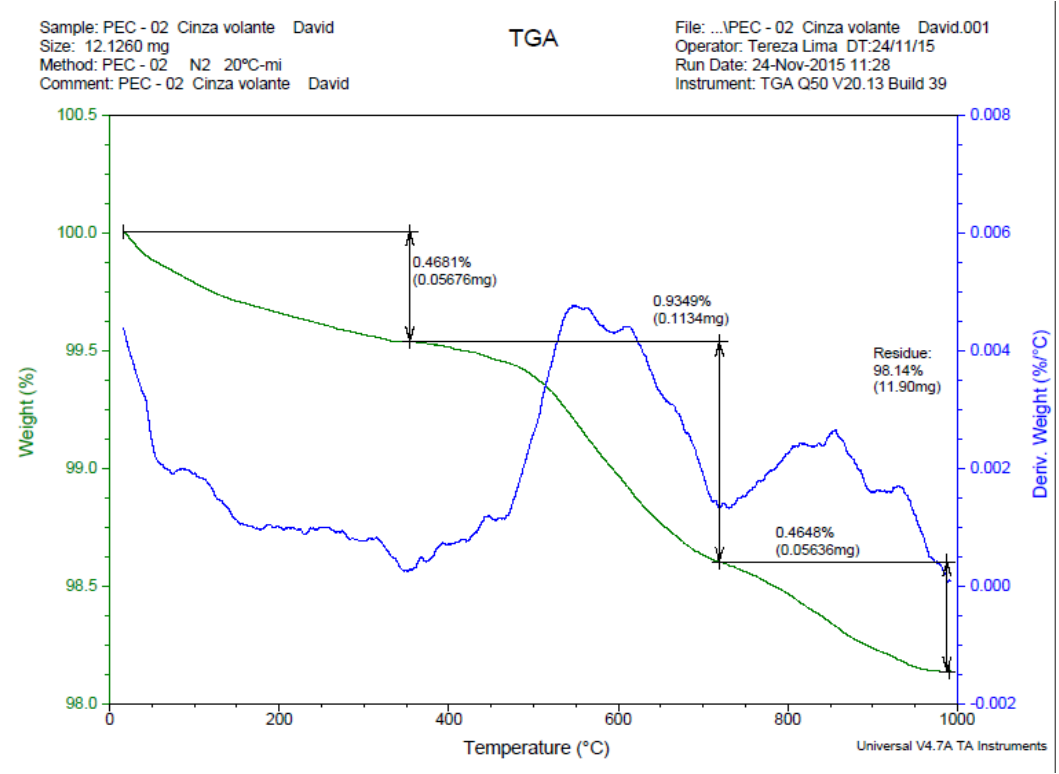

Figura 4: Análise termogravimétrica (TGA) da cinza CV1.

Na primeira etapa, entre a faixa de temperatura de $100^{\circ} \mathrm{C}$ a $180^{\circ} \mathrm{C}$, ocorre a perda de massa de $0,4681 \%$, associada a perda de água (umidade) e a decomposição de produtos voláteis e matéria orgânica residual do carvão. Para temperaturas superiores a $400^{\circ} \mathrm{C}$, inicia-se a decomposição de produtos à base de sulfatos. Estes resultados são compatíveis com os baixos teores de umidade (018\%) e compostos do trióxido de enxofre $(3,57 \%)$, já que em temperaturas superiores a $650^{\circ} \mathrm{C}$, tem-se a decomposição de substâncias contendo o enxofre, como $\mathrm{SO}_{2}$ e $\mathrm{SO}_{3}[66,67]$.

$\mathrm{Na}$ segunda etapa, de $350^{\circ} \mathrm{C}$ e $725^{\circ} \mathrm{C}$, a perda de massa foi de $0,9343 \%$, que pode ser associada à decomposição de fases baseadas no Silício e outros compostos voláteis presentes no material. Resultados estes compatíveis com o teor de dióxido de sílica de $50,33 \%$. Na faixa entre $500^{\circ} \mathrm{C}$ a $600^{\circ} \mathrm{C}$, observa-se um pico exotérmico, o qual pode ser associado à decomposição de carbono residual e, um pico endotérmico $\left(725^{\circ} \mathrm{C}\right)$, relacionado com a decomposição do Carbonato de cálcio, resultando no óxido de cálcio e liberando dióxido de carbono $[68,69]$.

Na terceira etapa, em temperaturas superiores a $725^{\circ} \mathrm{C}$ até $1000^{\circ} \mathrm{C}$, a perda de massa foi de $0,4648 \%$, que pode ser associada à continuidade da decomposição de fases de Carbonato de cálcio e o teor de carbono residual, em menor parcela do que o observado para a faixa até $725^{\circ} \mathrm{C}$. O alto teor de resíduos da CV1 corrobora com os resultados apresentados de resíduos insolúveis $(88,72 \%)$ e de perda ao fogo $(1,83 \%)$. Tais resultados indicam a boa eficiência da queima do carvão.

A Figura 5 apresenta a análise termogravimétrica da cinza CV2. A perda de massa total de 18,56\%, sendo observada em três etapas de decomposição térmica.

De acordo com a Figura 5, na primeira etapa de análise, entre a temperatura ambiente e $475^{\circ} \mathrm{C}$, observase uma perda de massa de 3,518\%, perda está associada a água presente no material (umidade), a decomposição de matéria orgânica residual e de compostos à base de sulfatos menos estáveis. Estes resultados são superiores aos apresentados para a cinza CV1, uma vez que a cinza CV2 apresenta trióxido de enxofre com $10,77 \%$. 


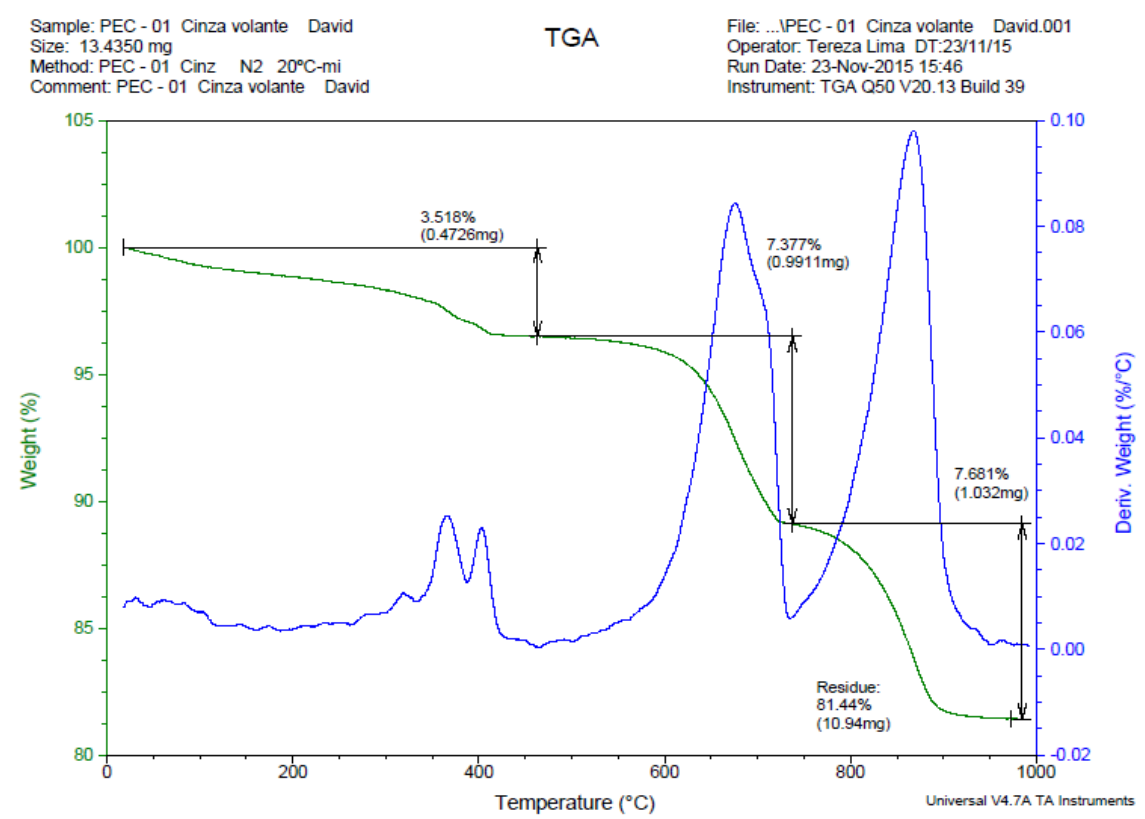

Figura 5: Análise termogravimétrica (TGA) da cinza CV2.

$\mathrm{Na}$ segunda e a terceira etapas, entre a temperatura de $475^{\circ} \mathrm{C}$ a $1000^{\circ} \mathrm{C}$, ocorreu uma perda de massa de $15,042 \%$, relacionada a decomposição de fases menos estáveis de sílica, por volta de $600^{\circ} \mathrm{C}$ e a decomposição do Carbonato de cálcio e a volatilização do dióxido de carbono, referentes aos picos endotérmicos em $750^{\circ} \mathrm{C}$ e $950^{\circ} \mathrm{C}[68,69]$.

Verificou-se também a existência de picos exotérmicos, possivelmente associados à decomposição do carbono residual, em $680^{\circ} \mathrm{C}$ e $845^{\circ} \mathrm{C}$. Em ambas as fases de decomposição térmica, observa-se a perda de massa na segunda etapa de $7,377 \%$ e $7,681 \%$ na terceira etapa. Acredita-se que a perda de massa total $(18,56 \%)$ tenha relação com os teores de resíduos insolúveis $(57,90 \%)$ e a perda ao fogo $(6,57 \%)$ apresentado pela cinza CV2.

\subsection{Análise mineralógica por DRX das Cinzas da combustão de carvão mineral}

As análises dos difratogramas permitem a caracterização mineralógica das cinzas CV1 e CV2, buscando a identificação das fases cristalinas presentes nas amostras avaliadas. Os difratogramas são apresentadas nas Figuras 6 e 7.

Em ambos os difratogramas, observam-se fases cristalinas, como o quartzo e a mulita, fases estas comumente encontradas em cinzas da combustão de carvão mineral [70]. Verificam-se também Backgrounds (halos), no intervalo entre $15^{\circ}$ a $40^{\circ}(2 \Theta)$, característicos de fases amorfas, presença de matéria orgânica, carbono residual e fases vítreas de aluminossilicatos [49, 71]. 


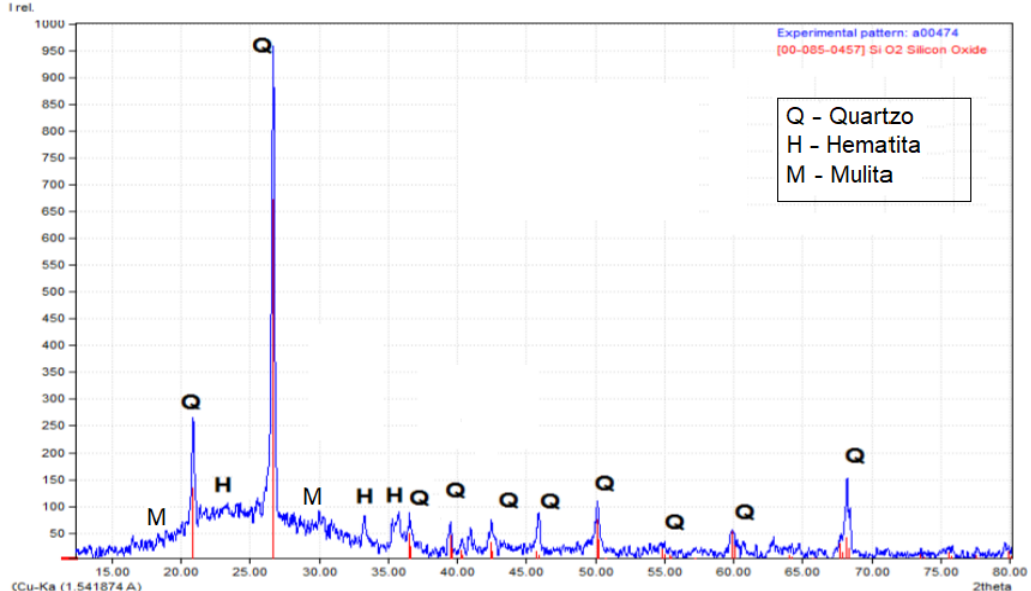

Figura 6: Difratograma da cinza CV1.

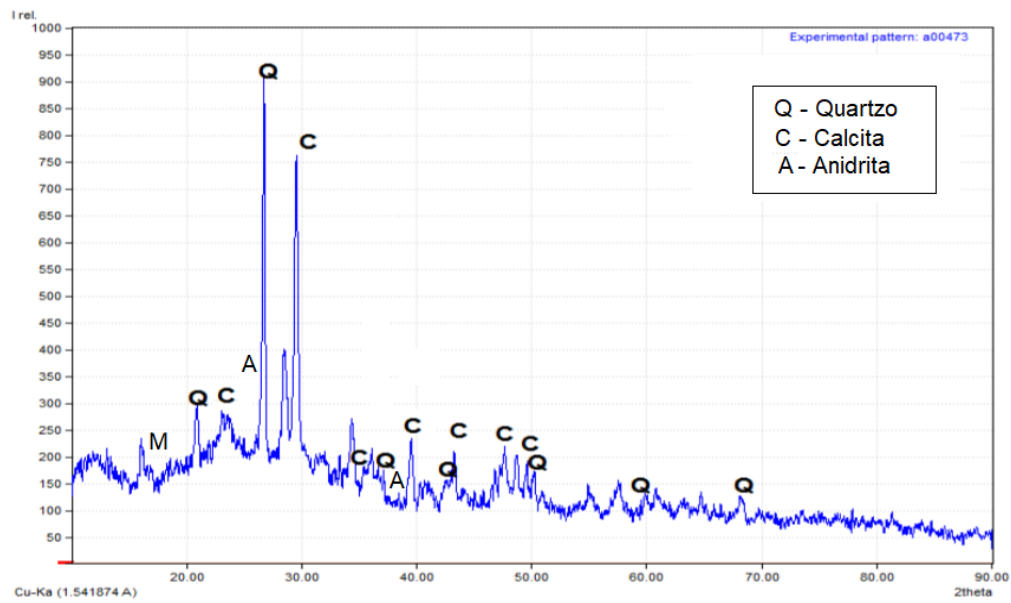

Figura 7: Difratograma da cinza de CV2.

Para a cinza CV1, destaca-se a presença de hematita e do quartzo, fases estas que podem ser formadas em processos de queima do carvão em temperaturas inferiores a $1000^{\circ} \mathrm{C}$. Uma vez que, em temperaturas de queima inferiores a $1000^{\circ} \mathrm{C}$, algumas fases cristalinas ou amorfa, como a hematita e o quartzo podem se manter após a queima do carvão mineral [71].

Para a cinza CV2, verificam-se a formação de fases cristalinas como a Calcita e a Anidrita [71, 72], provenientes do processo dessulfuração da combustão do carvão mineral (FGD), onde insere-se o carbonato de cálcio no processo de queima do carvão, liberando o dióxido de carbono e formando o óxido de cálcio que reage com o dióxido de enxofre gerando como produto o sulfato de cálcio [54]. Resultado coerente com os dados de análise química por FRX, como o alto teor de trióxido de enxofre $\left(\mathrm{SO}_{3}\right)$ na cinza CV2 (10,78\%).

Quanto à utilização das cinzas em compostos cimentícios, vale ressaltar os minerais cristalinos, as partículas de carbono não calcinadas e partículas não cristalinas de aluminossilicato, presentes em amostras de cinzas de combustão de carvão mineral, que apresentam diferentes velocidades e mecanismos de reação com os compostos da matriz cimentícia alterando a formação de fases hidratadas nestes compostos [73]. Assim, as principais fases que podem alterar a reatividade das cinzas em matrizes cimentícias são o quartzo, a mulita, a hematita, a ferrita, o aluminato tricálcico e a cal $[73,74]$.

\subsection{Avaliação da atividade pozolânica das cinzas da combustão de carvão mineral}

Os resultados dos requisitos químicos, para a avaliação da atividade pozolânica das cinzas CV1 e CV2 são apresentados na Tabela 6. 
Tabela 6: Resultados e comparação dos requisitos normativos de atividade pozolânica das cinzas da combustão de carvão mineral quanto às propriedades químicas.

\begin{tabular}{c|c|c|c}
\hline PROPRIEDADES QUíMICAS & REQUISITO NORMATIVO (\%) & CV1 (\%) & CV2 (\%) \\
\hline $\mathrm{SiO}_{2}+\mathrm{Al}_{2} \mathrm{O}_{3}+\mathrm{Fe}_{2} \mathrm{O}_{3}$ & $\geq 70,0$ & 84,03 & 51,98 \\
\hline $\mathrm{SO}_{3}$ & $\leq 5,0$ & 1,64 & 10,77 \\
\hline Perda ao fogo & $\leq 3,0$ & 0,35 & 0,88 \\
\hline Umidade & $\leq 6,0$ & 1,83 & 6,57 \\
\hline Álcalis $\left(\mathrm{Na}_{2} \mathrm{O}\right)$ & $\leq 1,5$ & 1,35 & 0,75 \\
\hline
\end{tabular}

A Tabela 7 apresenta os resultados para a avaliação da atividade pozolânica quanto às propriedades físicas das cinzas de carvão mineral CV1 e CV2.

Tabela 7: Resultados e comparação dos requisitos normativos da atividade pozolânica das cinzas da combustão de carvão mineral quanto às propriedades físicas.

\begin{tabular}{|c|c|c|c|c|}
\hline PROPRIEDADES FÍSICAS & REFERÊNCIA NORMATIVA & $\begin{array}{l}\text { CIMENTO DE } \\
\text { REFERÊNCIA }\end{array}$ & CV1 & CV2 \\
\hline Material retido na peneira $45 \mu \mathrm{m}$ & $<20,0 \%$ & - & $1,26 \%$ & $13,18 \%$ \\
\hline $\begin{array}{l}\text { Desempenho com cimento Por- } \\
\text { tland aos } 28 \text { dias de cura [32] }\end{array}$ & $\begin{aligned} \geq & 90,0 \% \text { da resistência do } \\
& \text { cimento de referência }\end{aligned}$ & 26,76 Мра & $\begin{array}{l}28,31 \\
\text { Mpa }\end{array}$ & 26,90 Mpa \\
\hline $\begin{array}{l}\text { Atividade pozolânica com cal aos } \\
\qquad 7 \text { dias [31] }\end{array}$ & $\geq 6,0 \mathrm{Mpa}$ & - & 7,6 Mpa & 6,6 Mpa \\
\hline
\end{tabular}

De acordo com os dados referentes às Tabelas 6 e 7, a cinza CV1 atende a todos os requisitos químicos e físicos indicados pela ABNT NBR 5751:2015 [32] e ABNT NBR 5752:2014 [32]. Quanto a cinza de carvão mineral CV2, o desempenho químico não foi satisfatório, uma vez que não foram atendidos os requisitos mínimos quanto ao somatório dos óxidos de $\mathrm{Si}$, $\mathrm{Al}$ e $\mathrm{Fe}\left(\mathrm{SiO}_{2}+\mathrm{Al}_{2} \mathrm{O}_{3}+\mathrm{Fe}_{2} \mathrm{O}_{3}\right)$ com 51,98\%, inferior ao mínimo de 70,0\%, e o teor de trióxido de enxofre $\left(\mathrm{SO}_{3}\right)$ com 10,77\%). Atendendo apenas aos requisitos de teor de umidade, com valor inferior a 3,0\% e álcalis $\mathrm{Na}_{2} \mathrm{O}$ com $0,75 \%$ [46].

Neste sentido, pode-se relacionar dos resultados dos requisitos químicos com a atividade e pozolânica e o teor de dióxido de silício $\left(\mathrm{SiO}_{2}\right)$, onde a combina-se com a cal livre $(\mathrm{CaO})$ e a água, formando quantidades suplementares de Silicato de Cálcio Hidratado (CSH) [57]. Com isso, cinzas com teores inferiores a 35\% de dióxido de silício $\left(\mathrm{SiO}_{2}\right)$ são praticamente inativas como pozolanas, reduzindo a utilização em materiais cimentícios [75]. As referências apresentadas são compatíveis com os teores de dióxido de silício, para a CV1 de $50,44 \%$ e $29,98 \%$ para a cinza CV2.

A cinza CV2 apresentou-se dentro dos limites normativos, para os requisitos físicos de atividade pozolânica. No entanto, não são suficientes para a comprovação da atividade pozolância. Com isso, a cinza CV2 pdoe apresentar baixa reatividade, redução do efeito fíller e nucleador dos grãos de cinzas, retrações por secagem e ataques por sulfatos ou comprometimento da resistência mecânicas de compostos cimentícios formulados [76]. Segundo Mehta (1996) [77], alguns autores criticam a classificação adotada pela norma brasileira quanto ao teor mínimo de $70 \%$ para o somatório dos óxidos de $\mathrm{Si}$, $\mathrm{Al}$ e $\mathrm{Fe}\left(\mathrm{SiO}_{2}+\mathrm{Al}_{2} \mathrm{O}_{3}+\mathrm{Fe}_{2} \mathrm{O}_{3}\right)$. Apontam que parte deste percentual pode está na forma amorfa (não apresentando atividade pozolânica) e sim, propriedades cimentantes. Classificando as cinzas apenas quanto à pozolanicidade, desconsiderando os benefícios proporcionados pelos maiores teores de óxido de cálcio presentes em cinzas da combustão de carvão mineral. Esta justificativa pode ajudar à explicar o atendimento da cinza CV2 quanto aos requisitos físicos para a avaliação da atividade pozolânica. 


\section{CONCLUSÕES}

Os ensaios de caracterização das cinzas de combustão de carvão mineral CV1, indicam o atendimento aos requisitos químicos para a classificação como cinza volante tipo $\mathrm{C}$, quanto aos requisitos referidos nas normas ABNT NBR 12653:2014 [46] e ASTM C618: 2012 [53]. Destacam-se os parâmetros de somatório dos óxidos de silício, alumínio e ferro $\left(\mathrm{SiO}_{2}+\mathrm{Al}_{2} \mathrm{O}_{3}+\mathrm{Fe}_{2} \mathrm{O}_{3}\right)$ totalizando $83,91 \%$, valor superior ao mínimo de $70 \%$, baixos teores de trióxido de enxofre $\left(\mathrm{SO}_{3}\right)$ com $1,64 \%$ e o teor de álcalis $\mathrm{Na}_{2} \mathrm{O}$, inferior a $1,5 \%$.

A cinza CV1 apresentou um baixo teor de umidade, finura pelo método de permeabilidade ao ar de $8220 \mathrm{~cm}^{3} / \mathrm{g}$, resultado compatível com a amplitude granulométrica de $0,2 \mu \mathrm{m}$ a $5,0 \mu \mathrm{m}$, que podem ser relacionados com uma maior área superficial. A cinza CV1 apresenta morfologia esférica com mineralogia composta por fases de hematita, quartzo e mulita e perda de massa de 1,83\%, observada por análise termogravimétrica. Em função das características químicas e das propriedades físicas, a cinza CV1 apresentou atividade pozolânica quanto a todos os requisitos normativos.

No que se refere a cinza CV2, não foram atendidos os requisitos químicos para a classificação como cinza volante ou atividade pozolânica. Devido ao baixo teor de soma dos óxidos de silício, alumínio e ferro $\left(\mathrm{SiO}_{2}+\mathrm{Al}_{2} \mathrm{O}_{3}+\mathrm{Fe}_{2} \mathrm{O}_{3}\right)$ com 50,33\% e alto teor de trióxido de enxofre $\left(\mathrm{SO}_{3}\right)$ de $10,77 \%$, relacionado ao processo de dessulfuração de gases de chaminé - FGD, adotado na UTE do Pecém/CE. A distribuição granulométrica da cinza CV2 ficou entre $0,15 \mu \mathrm{m}$ a $200 \mu \mathrm{m}$. Na análise térmica, observou uma perda de massa de $18,56 \%$ para a cinza CV2 e a mineralogia indicou a presença de quartzo, mulita, calcita e anidrita. Vale salientar que a cinza CV2 atendeu aos requisitos físicos de avaliação da atividade pozolânica, quanto aos parâmetros de desempenho com cimento Portland aos 28 dias de cura e com cal aos 7 dias. Este resultado pode ser compatível com o alto teor óxido de cálcio $(31,06 \%)$ indicativo de ação cimentante da cinza CV2.

Assim, conclui-se que a principal contribuição do trabalho advém da caracterização química e física das cinzas da combustão de carvão mineral das UTEs do Pecém/CE, que possibilitam a classificação das cinzas quanto ao tipo e a avaliação da atividade pozolânica. Com isso, possibilitando a utilização destes resíduos de maneira segura e sustentável, como o uso em materiais cimentícios, reduzindo o risco ambiental provocado pelo acúmulo das cinzas.

\section{AGRADECIMENTOS}

Ao apoio técnico e orientações fundamentais para a realização da pesquisa: A equipe do LABIN/UFRN e da indústria de cimentos APODI.

\section{BIBLIOGRAFIA}

[1] IEA - International Energy Agency. Key World Energy Statistics 2020. Disponível em :< https://www.iea.org/reports/global-energy-review-2020/coal >. Acesso em junho de 2020.

[2] SILVA, W.B.S, BARROSO, S.H.B., CABRAL, A.E.B., "Avaliação da aplicação de cinzas pesadas de termelétrica em blocos intertravados de concreto para pavimentos", Revista Matéria, v.25, n.01, 2020.

[3] ANEEL - Agência Nacional de Energia Elétrica. Banco de Informações da Geração (BIG), 2019. Disponível em:http://www.aneel.gov.br/aplicacoes/capacidadebrasil/capacidadebrasil.cfm. Acesso em: 12 jun. 2020.

[4] EPE - Empresa de Pesquisas Energéticas, Balanço energético nacional, In: Report síntese, ano base 2016,Rio de Janeiro, RJ, 2017.

[5] FALLAVENA, V.L.V., ABREL, C.S., INÁCIO, T.D., et al., "Caracterização detalhada de material de referência certificado de carvão brasileiro", Química Nova, v.36, n.06, 2013.

[6] BIELOWICZ, B., "Petrographic characteristics of coal gasification by-products from high volatile bituminous coal", Energies, 2020.

[7] OIKAWA, K., YONGSIRI, C., TAKEDA, K., et al., "Seawater flue gas desulfurization: Its technical implications and performance results", Environ. Prog., 2003.

[8] ZHANG, C., YANG, L. "One-dimensional simulation of synergistic desulfurization and denitrification processes for electrostatic precipitators based on a fluid-chemical reaction hybrid model", Energies, 2018. 
[9] SABEDOT, S., SUDSTRON, M.G., BOER, S.C., et al., "Caracterização e aproveitamento de cinzas de combustão de carvão mineral gerados em usinas termelétricas", In: anais do III Congresso Brasileiro de Carvão Mineral, Gramado, 2011.

[10] MARTINS, J.L. Aproveitamento de cinza de carvão mineral na agricultura. Universidade Federal do Rio Grande do Sul, Porto Alegre, 2001.

[11] SRIVASTAVA, R.K., JOZEWICK, W., "Fuel gas desulfurazation: The state of the art", Journal of the Air \& Waste Management Association, 2011.

[12] LONG, N.V.D., LEE, D.Y., JIN, K.M. et al., "Advanced and intensified seawater flue gas dessulfurization processes : Recent developments and improvements", Energies, 2020.

[13] CACURO, T.A., WALDMAN, W.R., "Cinzas da queima de carvão de biomassa: aplicações e potencializades", Revista Virtual de Química, v.7, n.6, pp 2154-2165, 2015.

[14] HUI, Li, et al., "Microestructure and performance of fly ash micro-beads in cementitious material system", Construction and Building Materials, v. 52, pp.422-427, 2014.

[15] HENDRICKS, F., A NIJKERK, A., VAN KOPPEN, A.E., "The building cycle", Aesneas Technical Publishers, 2000.

[16] BIELOWICZ, B., "Ash characteristics and selected critical elements (Ga, Sc, V) in coal and ash in polish deposits", Resources, 2020.

[17] KIHARA, Y., MARCIANO, J., "Qualidade e produtividade na indústria de cimento", In: Informativo Abesc, 1995.

[18] CHIES, F., SILVA, N.I.W., ZWONOK, O., "Desenvolvimento de blocos e tijolos a apartir de cinzas de fundo de carvão" CIPECAL. In: ROCHA, J. C., JOHN, V. M. "Utilização de resíduos na construção habitacional", ANTAC, v.4, 2003.

[19] CIENTEC, Fundação de Ciência e Tecnologia, "Botelim técnico 36: Quantificação das cinzas de carvão fóssil produzidas no Brasil”, 2016.

[20] BARROS, K.S., "Estudo de cinzas de uma termelétrica da região metropolitana de Fortaleza-CE para aplicação m camadas granulares de pavimentos", Tese de M. Eng., PETRAN/UFC, Fortaleza, CE, Brasil, 2015.

[21] OBERSCHELP, C., PFISTER, S., RAPTIS, C.E., et al., "Global emission hotpots of coal power generation", Nature Sustentability, v. 2, pp.113-121, 2019.

[22] KOCAK, Y., NAS, S..,"The effect of using fly ash on the strenght and hydration characteristic of blended cements", Construction and Building Materials, n. 73, pp.25-32, 2014.

[23] KARAYANNIS, V.G., MOUTSATSOU, A.K., KATSIKA, E.L., "Synthesis of microwave-sintered ceramics from lignite fly and bottom ashes", Journal of Ceramic Processing Research, n14. v 1, pp. 45-50, 2013.

[24] LAV, A.H., LAV, M.A., GÖKTEPE, B.A., "Analysis and design of a stabilized fly ash as pavement base material", Fuel, pp 2349-2370, 2006.

[25] OJHA, K.,, PRADHAN, N.C.; SAMANTA, A.N.,"Zeolite from fly ash: synthesis and characterization”, Bulletin of Materials Science, pp 555-564, 2004.

[26] WANG, S.. ZHANG, C., CHEN, J., "Utilization of coal fly ash for the production of glass-ceramics with unique performances: a brief review." Journal of Materials Science \& Technology, pp1208-1212, 2014.

[27] CAMÕES, A., ROCHA, P., JALALI, S., et al., "High performance concrete using fly ash.", ACI Special Publication, 2002.

[28] CRISTINA, A., SANJUÁN, M., MENÉNDEZ, E., "Coal bottom ash for Portland cement production", Advances in Materials Science and Engineering, pp 1-7, 2017.

[29] XAVIER, M.F., FERREIRA, W.L., BRANCO, V.T.F., “Avaliação do uso de cinzas de carvão mineral como melhorador de adesividade em misturas asfálticas", Revista Matéria, v.25, n.01, 2020.

[30] BAYAT, B., "Comparative study of adsorption properties of Turkish fly ashes. II. The case of chromium(VI) and cadmium(II)", Journal of Hazard Mater, 3898, pp. 1-16, 2002.

[31] RAYSMAN, V.L., "Technology for chemical-metallurgical coal ash utilization", Energy and Fuels, v. 
11, pp. 761-773, 1997.

[32] ASSOCIAÇÃO BRASILEIRA DE NORMAS TÉCNICAS-ABNT. NBR 5751: Materiais pozolânicos Determinação da atividade pozolânica com cal aos sete dias. Rio de Janeiro, 4 p. 2015.

[33] ASSOCIAÇÃO BRASILEIRA DE NORMAS TÉCNICAS-ABNT. NBR 5752: Materiais pozolânicos Determinação do índice de desempenho com cimento Portland aos 28 dias. Rio de Janeiro, 4 p. 2014.

[34] ASSOCIAÇÃO BRASILEIRA DE NORMAS TÉCNICAS-ABNT. NBR 14656: Cimento Portland e matérias-primas - Análise química por espectrometria de Raios X - Método de ensaio. Rio de Janeiro, 6 p. 2001.

[35] ASSOCIAÇÃO BRASILEIRA DE NORMAS TÉCNICAS-ABNT. NBR NM 24: Materiais pozolânicos - Determinação do teor de umidade. Rio de Janeiro, 3 p. 2003.

[36] ASSOCIAÇÃO BRASILEIRA DE NORMAS TÉCNICAS-ABNT. NBR 7227: Cimento Portland Determinação de óxido de cálcio livre pelo etileno glicol - Método de ensaio. Rio de Janeiro, 3 p. 1989.

[37] ASSOCIAÇÃO BRASILEIRA DE NORMAS TÉCNICAS-ABNT. NBR NM 15: Cimento Portland Análise química - Determinação de resíduo insolúvel. Rio de Janeiro, 3p. 2012.

[38] ASSOCIAÇÃO BRASILEIRA DE NORMAS TÉCNICAS-ABNT. NBR NM 18: Cimento Portland Análise química - Determinação de perda ao fogo. Rio de Janeiro, 4 p. 2012.

[39] ASSOCIAÇÃO BRASILEIRA DE NORMAS TÉCNICAS-ABNT. NBR NM 23: Cimento Portland e outros materiais em pó - Determinação da massa específica. Rio de Janeiro, 5 p. 2001.

[40] ASSOCIAÇÃO BRASILEIRA DE NORMAS TÉCNICAS-ABNT. NBR 16372: Cimento Portland e outros materiais em pó - Determinação da finura pelo método de permeabilidade ao ar (método de Blaine). Rio de Janeiro, 11 p. 2015.

[41] NUHU, S., LADAN, S., MUHAMMAD, A.U., "Effects and control of chemical composition of clinker for cement production", International Journal of Control Science and Engineering, v. 10, n1, pp. 16-21, 2020.

[42] KIATTIKOMOL, K., JATURAPITAKKUL, C., TANGPAGASIT, J., "Effect of insoluble residue on properties os Portland cement", Cement and Concrete Research, v. 30, n8, pp. 1209-1214, 2000.

[43] CIENTEC. C-028: Materiais cerâmicos - Determinação da perda ao fogo. Porto Alegre, 2 p. 1995.

[44] MALLMAN, J.E.C., Metodologia de dosagem racional do concreto compactado com rolo (CCR) usando cinza volante de carvão e cal hidratada em substituição ao cimento Portland, Tese de D. Eng., PPGEC/UFRGS, Porto Alegre, RS, Brasil, 2018.

[45] CANeVAROLO, S.V. JR., Técnicas de caracterização de polímeros, São Paulo, Artliber, 2003.

[46] ASSOCIAÇÃO BRASILEIRA DE NORMAS TÉCNICAS-ABNT.NBR 12653: Materiais pozolânicos Requisitos. Rio de Janeiro, 6 p. 2014.

[47] BENTZ, D.P., JONES, S.Z.; SNYDER, K.A., "Design and performance of ternary blend high-volume fly ash concretes of moderate slump", Construction and Building Materials, pp. 409-415, 2015.

[48] BUI, P.T., et al., "A study on pozzolanic reaction of fly ash cement paste activated by an injection of alkali solution", Construction and Building Materials, pp. 28-34, 2015.

[49] HOPPE FILHO, J., Sistemas cimento, cinza volante e cal hidratada: Mecanismo de hidratação, microestrutura e carbonatação do concreto, Tese D. Eng., POLI/USP, São Paulo, SP, brasil, 2008.

[50] KABAY, N., et al., "Properties of concrete with pumice powder and fly ash as cement replacement materials", Construction and Building Materials, pp. 1-8, 2015.

[51] MEJÍA, J.M., et al., "Preparation and characterization of a hybrid alkaline binder based on a fly ash with no commercial value", Construction and Building Materials, pp. 346-352, 2015.

[52] SHAIKH, F.U.A., SUPIT, S.W.M., "Compressive strength and durability properties of high volume fly ash (HFVA) concretes containing ultrafine fly ash (UFFA)", Construction and Building Materials, pp. 192$205,2015$.

[53] AMERICAN SOCIETY FOR TESTING AND MATERIALS-ASTM. C618-12a : West Conshohocken, p. 5. 2012.

[54] AHMARUZZAMAN, M., "A review on the utilization of fly ash", Progress in Energy and Combustion Science, pp. 327-363, 2009. 
[55] ALONSO, J.L., WESCHE, K., "Characterization of fly ash. Fly ash in concrete: properties and performance", RILEM, pp. 3-23, 1991.

[56] LAWRENCE, P., CYR, M., RINGOT, E., "Mineral admixture in mortars. Effect of inert materials on short-term hydration", Cement and Concrete Research, v. 33, n. 12, pp. 1939 - 1947, 2003.

[57] AZEVEDO, A.F.F.L.C., Betões de elevado desempenho com incorporação de cinzas volantes, Tese D. Eng., Universidade do Minho. Guimarães, 2002.

[58] DAL MOLIN, D.C.C., Adições Minerais. In: ISAIA, G. C., Concreto: ciência e tecnologia, São Paulo, IBRACON, v. I, 2011. Cap. 8, pp. 261-309, 2011.

[59] KIM, D., "Effects odf adjusting for particles-size distribution of cement on strength development of concrete", Advances in Materials Science and Engineering, 2018.

[60] ABRÃO, P.C.R., O uso de pozolanas como materiais cimentícios suplementares: disponibilidade, reatividade, demanda de água e indicadores ambientais, Tese de M. Ciências, POLI/USP, São Paulo, SP, Brasil, 2019.

[61] NORMA PORTUGUESA. EN 450: Cinzas volantes para betão; Parte 1: Definição, especificações e critérios de conformidade. 2012.

[62] ITSKOS, G., ITSKOS, S., KOUKOUZAS, N., "Size fraction characterization of highlycalcareous fly ash”, Fuel Processing Technology, pp. 1558-1563, 2010.

[63] STRZALKOWSKA, E., "Morphology and chemical composition of mineral matter presente in fly ashes of bituminous coal and lihnite", International Journal of envirenmental Science and Technology, 2020.

[64] LEE, K.H., YANG, K.H., MUN, J.H., et al., "Effect of sand contente on the workability and mechanical properties of concrete using bottom ash and dredged soil-based artificial lightweight aggregates", International Journal of concrete, Structural Materials, n13, pp 115-127, 2019.

[65] KIM, Y.H., KIM, H.Y., YANG, K.H., et al., "Evaluation of workability and mechanical properties of bottom ash aggregate concrete", Applied Sciences, 2020.

[66] CONCER., P.H., Obtenção dos parâmetros cimentícios da reação de decomposição e oxidação térmica da pirita, demanda de água e indicadores ambientais, Tese de M. Eng. Química. PPGEQ/UFSC, Florianópolis, SC, Brasil, 2013.

[67] VASSILEV, S.V., TASCÓN, J.M.D., "Methods for Characterization of Inorganic and Mineral Matter in Coal: A Critical Overview", Energy \& Fuels, v. 17, pp. 271-281, 2003.

[68] CAPANA, A.S., Caracterização e estudo do comportamento térmico de resíduo (lodo) proveniente de estações de tratamento de água e de esgotos do município de Araraquara-SP, Tese de M. Química. IQ/UNESP, Araraquara, SP, Brasil, 2009.

[69] MAHON, D., CLAUDIO, G., EAMES, P., "A experimental study of the decomposition and carbonation of magnesium carbonate for médium temperature thermochemical energy storage”, Energies, 2021.

[70] HUANG, F., XIN, S., MI, T., et al., "Investigation on the transformation behaviours of Fe-bearing minerals of coal in $\mathrm{O}_{2} / \mathrm{CO}_{2}$ combustion atmosphere containing $\mathrm{H}_{2} \mathrm{O}$ ", Royal Society of Chemistry, 2021.

[71] WU. P., LI, P., ZHUANG, X., et al., "Mineralogical and environmental geochemistry of coal combustion products from Shenhuo and Yihua power plants in Xinjiang autonomous region, Northwest China", Mineral, 2019.

[72] ERARSLAN, C., ORGUN, Y., "Mineralogical and geochemical characteristic of coal ash from the Northwest Thrace region, Turkey: a case study", Arabian Jornal of Geosciences, 2017.

[73] WARD, C.R., FRENCH, D., "Relation between coal and fly ash mineralogy, based on quantitative Xray diffraction methods", In: Proc. World Coal Ash Conf., Lexington, 2005.

[74] CHANCEY, R.T., STUTZMAN, P., JUENGER, M.C.G., et al., "Comprehensive phase characterization of crystalline and amorphous phases of a class F fly ash", Cement and Concrete Research , n. 40, pp146-156, 2010.

[75] ALONSO, J.L., WESCHE, K., “Characterization of fly ash: Properties and performance.”, RILEM, pp 323, 1991. 
[76] CHINDAPRASIRT, P., HOMWUTTIWONG, S., et al., "Influence of fly ash fineness on strenght, drying shrinkage and sulfafe resistance of blended cement mortar", Cement and Concrete Research, pp. 1087 - 1092, 2004.

[77] MEHTA, P.K, MONTEIRO P.M., Concrete: Microestructure, properties and materials. University Of California, Berkeley, 1996.

\section{ORCID}

Miguel Adriano Gonçalves Cirino

https://orcid.org/0000-0001-5441-8080

Antônio Eduardo Bezerra Cabral

https://orcid.org/0000-0001-6394-1164

David Alison Araújo Silva

https://orcid.org/0000-0002-8732-3157

Kalil Nobrega Hissa Sampaio

https://orcid.org/0000-0001-6834-2013 